\title{
Rats' barpressing in the presence of free food as a function of fixed ratio schedules*
}

\author{
ROBERT D. TARTE and CHARLES R. VERNON \\ Lniversity of Vevada. Las Vegas, Nev. 89154
}

Nine rats were tested in a choice situation in which they could obtain food pellets by barpressing at various FR schedules or take it freely from a dish. All animals were given barpress training at FR $1,3,5,7,9,11,13$, $15,17,19,21$, and again at FR 1 , and tested in the choice situation at FR $1,5,9,13,17,21$, and again at FR 1. The mean percentage of food pellets obtained by barpressing in the presence of free food decreased in a significant linear fashion from $65 \%$ at FR 1 to $11 \%$ at FR 21, and then increased to $69 \%$ for the last choice session at FR 1. A direct relationship was demonstrated between the amount of work involved in barpressing for food and the percentage of food taken by barpressing.

A number of studies have shown that rats will barpress for food in the presence of identical, freely available pellets, and in many cases perfer to obtain food by barpressing to taking it freely (Jensen, 1963; Neuringer, 1969; Carder \& Berkowitz, 1970; Tarte \& Snyder, 1972). Carder \& Berkowitz (1970) demonstrated that the animals' preference varied as a function of work required. At FR 1 and FR 2, the animals barpressed for over $80 \%$ of their food. At FR 10, the animals barpressed for less than $20 \%$ of their food. When the animals were returned to a FR 1 schedule, they again pressed for about $80 \%$ of their food.

Singh (1970) found that animals, in a shuttlebox choice situation. preferred to barpress at FR 1 for $88 \%$ of the food obtained, at FR 3 for $68 \%$ of the food, and at FR 11 for $73 \%$. Singh showed that the preference for barpressing did not vary as a function of amount of work required at FR schedules equivalent to those of the Carder \& Berkowitz (1970) study. The difference in results may have been due to the differences in apparatus and training procedures. In another experiment, Singh (1970) tested rats in a choice situation in which "free-loading was made more attractive." Animals could obtain free food 12.5\%, 25\%, or $50 \%$ faster than they could obtain food by barpressing. Under these conditions, rats barpressed for $73 \%, 70 \%$, and $39 \%$ of their food, respectively.

Davidson (1971) found that rats trained at FR 10 showed no significant decrease in percentage of barpressing in the presence of free food over 87 days of testing. During the 87 days, the animals continued to barpress at a mean rate equivalent to that recorded on the first days.

The present study was designed to examine systematically the amount of rats' barpressing in the

*This research was supported by a grant from the University of Nevada to the first author. presence of free food as a function of fixed ratio schedules. The design was structured to include a wider range of FR schedules with more intermediate ones than previously had been tested.

\section{METHOD \\ Subjects}

Nine naive male albino rats, weighing approximately $250 \mathrm{~g}$ each, were used as Ss. The animals were housed one to a cage throughout the experiment.

\section{Apparatus}

Four standard Lehigh Valley operant chambers were used. A small rodent lever was mounted on the right front wall of each chamber; $45-\mathrm{mg}$ Noyes food pellets were delivered by a tube mounted in the center of the front wall and were deposited in a metal food dish mounted to the floor. An identical free food dish was mounted in the left rear corner of the chambers.

\section{Procedure}

The animals were placed in 23-h deprivation schedules for 1 week prior to the start of training. Throughout the experiment, the animals were run for $1 \mathrm{~h}$ per day, and then given access to lab chow in their home cages for $1 / 2 \mathrm{~h}$ immediately after training. Water was always available in the home cages.

The training procedure was approximately that of Carder \& Berkowitz (1970). During the first 3 days of training, the levers were removed from the chambers and 400 free food pellets were placed in the free food dish. The animals had access to the food for $1 \mathrm{~h}$ each day. After the first 3 days, the levers were replaced, and the animals received barpress training for 6 days at FR 1 , with no free food present.

The day following the completion of the FR 1 training, the animals were placed in the chamber containing an operable bar and 400 food pellets in the free food dish. The numbers of pellets taken via the bar and those taken freely were recorded. The animals were than given two sessions of training at FR 3 and two sessions of training at FR 5, followed by one choice session at FR 5. Two training sessions at both FR 7 and FR 9 were followed by one choice session at FR 9. Two training days were then given at FR $11,13,15,17,19$, and 21 , and choice days interpolated at FR 13, 17, and 21. The animals, therefore, received lever training for two sessions at each level from FR 1 to FR 21, in jumps of FR 2, and were tested in the presence of free food at FR 1, FR 5, FR 9, FR 13, FR 17, and FR 21, jumps of FR 4. Following the choice day at FR 21, two additional training sessions were given at FR 1 , followed by one choice session at FR 1 .

\section{RESULTS \\ Training Days}

During barpress training sessions, the mean number of pellets consumed per animal per session varied from a low of 205 at FR 19 to a high of 315 at FR 3. The animals increased their consumption from FR 1 to FR 3 and then gradualiy decreased to FR 21 , followed by a sharp increase upon return to FR 1.

During training, the number of responses increased in a linear fashion from FR 1 to FR 21. The animals averaged 264 barpresses per day at FR 1 and 4,470 


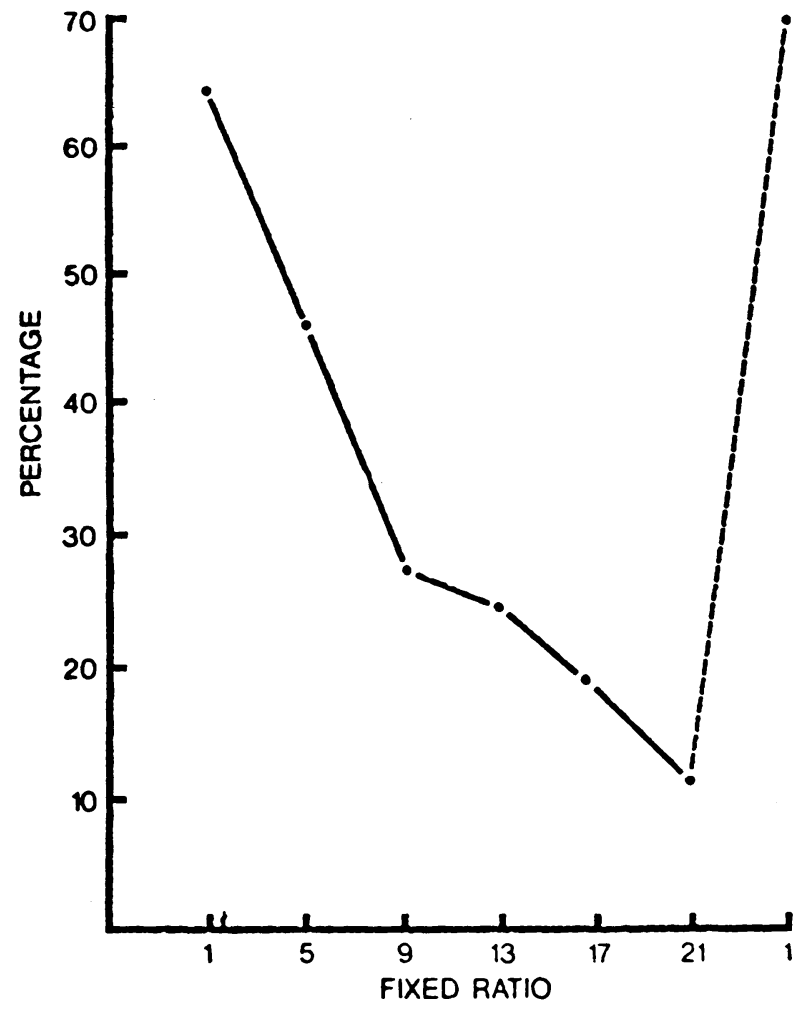

Fig. 1. Percentage of food pellets obtained by barpressing in the presence of free food as a function of FR schedules.

barpresses per day at FR 21. The latter number represents a mean of 89 barpresses $/ \mathrm{min}$. There were large individual differences between animals during training days. At FR 21, for example, one rat averaged only 3,087 barpresses per day, while another animal averaged 6,510 barpresses.

\section{Choice Days}

Choice days were given at FR 1, 5, 9, 13, 17, 21, and again at FR 1. The total number of food pellets consumed remained relatively constant throughout the choice days. The smallest number of food pellets consumed was 274 at FR 17, and the largest number consumed was 298 at FR 5. When the animals were tested at FR 1 at the end of the experiment, the number of food pellets consumed increased to 314 . From the initial FR 1 schedule to FR 9, there was a decrease from 191 to 80 pellets obtained via the bar per animal per session in the choice situation, and then a gradual, linear decrease to 30 pellets at FR 21. All pellets obtained by barpressing were consumed. The free food taken in the choice sessions was almost a perfect mirror image of the pellets obtained by barpressing, reflecting the nearly constant amount of total food consumed during the choice sessions. The mean number of free food pellets consumed increased from 10 at FR 1 to 213 at FR 9, and then increased linearly to 245 at FR 21.

Figure 1 shows the percentage of food pellets obtained by barpressing for the nine animals in the choice situation at various FR levels. The percentage of food pellets taken via the bar decreased from FR 1 $(64.5 \%)$ to FR 21 (10.9\%). The percentage of food taken via the bar during the last choice session at FR 1 increased to $69.3 \%$, or $4.8 \%$ above that of the first FR 1 choice session.

A one-way analysis of variance was conducted, using the FR levels frcm 1 through 21 as variables, and resulted in a significant $F$ ratio $(F=23.84, \mathrm{df}=5 / 40$, $p<.001)$. An orthogonal test of trend was applied to the percentages of barpressing from FR 1 through FR 21. A linear trend, significant at less than the .001 level, was found (Winer, 1971).

The mean number of barpresses during choice sessions increased from 191 at FR 1 to 910 barpresses at FR 13, and then decreased to 846 at FR 17 and 630 at FR 21, roughly an inverted-U function. While the grouped data appears very consistent, the individual rats varied greatly during the choice days. For example, at FR 21, the smallest percentage of food obtained by barpressing was $1 \%$, whereas the largest was $33 \%$. This variance was reflected in the difference in number of barpresses between rats in the FR 21 choice situation, which varied from 84 to 1,953 .

\section{DISCUSSION}

The percentage of food taken via barpressing in the choice situation appears to be a function of the FR schedules. As the FR schedules increased, the animals' consumption of free food increased, while food obtained via barpressing decreased. The total amount of food consumed remained constant throughout the choice days.

That rats continued to barpress for a percentage of their food in the choice situation did not appear to be a function of learning or practice, due to the small increase in barpressing between the first and last FR 1 choice sessions. If the learning of the barpress response was increasing during the experiment and was being moderated by the increasing FR schedules, the return to FR 1 probably should have resulted in a large increase in barpressing.

An additional study should be conducted, using independent groups of animals for each FR level of testing. That is, a comparable study to the present one would involve six groups of rats, each trained to one of the FR levels (FR 1, 5, 9, 13, 17, or 21 ), and then tested in the choice situation at that level only. A seventh group would be trained to FR 21 and then given additional training at FR 1 before being tested at FR 1, in order to control for the repeated exposure and testing at various levels found in the present study. This proposed study would require a large number of animals and the availability of a great deal of equipment. At any rate, the present study has demonstrated that the percentage of food obtained by barpressing in the presence of identical free food is a decreasing, linear function of the FR schedules from FR 1 to FR 21.

\section{REFERENCES}

Carder, B., \& Berkowitz, K. Preference for earned food in comparison with free food. Science, 1970, 167, 1273-1274.

Davidson, A. Factors affecting keypress responding by rats in the presence of free food. Psychonomic Science, 1971, 24, $135-137$.

Jensen, G. D. Preference for bar pressing over "freeloading" as a function of number of rewarded presses. Journal of Experimental Psychology, 1973, 65, 451-454.

Neuringer, A.J. Animals respond for food in the presence of free food. Science, $1969,166,399-401$. 
Singh. D. Preference for bar pressing to obtain reward over freeloading in rats and children. Journal of Comparative \& Physiological Psychology, 1970, 73, 320-327.

Tarte, R. D.. \& Snyder, R. L. Bar pressing in the presence of free food as a function of food deprivation. Psychonomic Science, 1972, 26, 169-170.
Winer, B. J. Statistical principles in experimental design. New York: McGraw-Hill, 1971.

(Received for publication September 28, 1973.)

\section{Recall of embedded sentences: Perceptual or performance deficit?*}

\section{RAYMOND BAIRD \\ Wright State Universitu. Davton. Ohio 45431}

College students attempted verbatim recall or recognition of sentences containing embedded or nonembedded relative clauses. Embedded sentences were more difficult than nonembedded in verbatim recall, but the sentence types were equally difficult in the recognition task, implying that the grammatical relations and meaning of both sentence types are recovered and entered into memory.

Sentences containing embedded relative clauses have been found to be more difficult to recall than sentences of the same length containing an equal number of nonembedded clauses (Miller \& Isard, 1964; Baird, 1973). Baird found this to be true both when the embedded construction was nested within the matrix sentence, e.g.,

(1) The friend whom the lawyer whom the attendant painted soaked liked the teller

and when the embedded construction was appended to the matrix sentence, e.g.,

(2) The child bit the man whom the doctor who chased the dog liked

Both these types of construction, called nested/embedded (N/E) and nonnested/embedded $(\mathrm{NN} / \mathrm{E})$, respectively, were more difficult to recall then their corresponding nonembedded forms, e.g.,

(3) The cat who saw the girl who paid the cashier caught the passenger (N/NE)

(4) The attendant painted the lawyer who soaked the friend who liked the teller (NN/NE)

*The author wishes to thank Dale Brinkman, John Koslick, and Douglas Finch for their assistance in this series of studies. This paper is sponsored by George E. Briggs, who takes full editorial responsibility for its contents.
Conjecture concerning the psychological reasons for these findings frequently center on the early grammatical analysis performed on the incoming signal as it is encoded in memory. For example, Chomsky (1965) writes: ". . . we must add other conditions on the perceptual device beyond mere limitation of memory. We might assume for example that the perceptual device has a stock of analytic procedures available to it, one corresponding to each type of phrase, and that is it organized in such a way that is is unable (or finds it difficult) to utilize a procedure $\phi$ while it is in the course of executing $\phi$ [p. 14]." Similarly, Miller \& Isard (1964) advance an explanation based on a computer analogy. This model, too, seems to be most applicable during the initial analysis of the incoming signal: "... suppose that, while the subroutine (for analyzing relative clauses) is being executed, a second such construction is encountered, so the subroutine is required to call itself. If this recursive feature were not available, confusion would result;... [p. 300]."

The general impression to be gained from these discussions is that the difference in recallability of embedded sentences relative to nonembedded sentences is the result of an incomplete grammatical analysis of the incoming string in the former. This imperfect analysis would involve, among other things, the failure to specify correctly various grammatical relationships, some of which would be necessary for apprehension of meaning. For example, from Example 1 above, it might be hypothesized from these models that the subject noun phrase-verb relationship holding between friend and liked might be weak if it were encoded at all. From the same example, the $\mathrm{NP}_{\text {subject }} \cdot \mathrm{V}$ relationship between lawyer and soaked might also be perceived inf requently and therefore not be seen in attempts to recall. The point here is that these associations, important for meaning, are weak. In short, recall of embedded constructions should show a deficiency in comprehension of these sorts of grammatical relations, and this deficiency is presumably attributable to an 